\title{
Ovarian, Fallopian Tube, and Primary Peritoneal Carcinoma pT3c TNM Finding v8
}

National Cancer Institute

\section{Source}

National Cancer Institute. Ovarian, Fallopian Tube, and Primary Peritoneal Carcinoma

pT3c TNM Finding v8. NCI Thesaurus. Code C139955.

Ovarian, fallopian tube, or primary peritoneal carcinoma with macroscopic peritoneal metastasis beyond the pelvis more than $2 \mathrm{~cm}$ in greatest dimension with or without metastasis to the retroperitoneal lymph nodes (includes extension of tumor to capsule of liver and spleen without parenchymal involvement of either organ). (from AJCC 8th Ed.) 